\title{
Transactional framework of sharecropping: empirical evidence
}

\begin{abstract}
Chew [Chew, Tek-Ann, 1991. Share contracts in Malaysian rubber smallholdings. Land Econ., 67: 85ï 98; Chew, Tek-Ann, 1993. The Transactional framework of sharecropping: further implications. Can. J. Agric. Econ., 41: 209ї 221.] proposed a transactional framework of sharecropping that accommodates both the Marshallian and the Cheungian equilibria. An important conclusion arising thereof is the hypothesis that Cheung's sharecropping equilibrium is the rarity while the Marshallian equilibrium is the norm. In this paper, we collated some recent evidences to verify this hypothesis. The evidences support the Marshallian equilibrium, thereby providing indirect support for the transactional framework of sharecropping.
\end{abstract}

Keyword: Sharecropping; Marshallian; Cheungian; Transactional; Shaban 